Review began 01/27/2022 Review ended 02/08/2022 Published 02/23/2022

๑) Copyright 2022

Lindner et al. This is an open access article distributed under the terms of the Creative Commons Attribution License CC-BY 4.0. which permits unrestricted use, distribution, and reproduction in any medium, provided the original author and source are credited.

\section{Severe Acute Respiratory Distress Syndrome (ARDS) or Severely Increased Chest Wall Elastance?}

\author{
Simon Lindner 1, 2 , Daniel Dürschmied ${ }^{1,2}$, Ibrahim Akin 1, 2 , Simone Britsch 1, 2 \\ 1. Department of Cardiology, Angiology, Haemostaseology and Medical Intensive Care, University Medical Center \\ Mannheim, Mannheim, DEU 2. European Center for Angioscience (ECAS) and German Center for Cardiovascular \\ Research (DZHK), Partner Site Heidelberg/Mannheim, Mannheim, DEU
}

Corresponding author: Simon Lindner, simon.w.lindner@gmx.de

Categories: Anesthesiology, Emergency Medicine, Internal Medicine

Keywords: transpulmonary pressure, covid-19, esophageal manometry, extracorporeal membrane oxygenation, acute respiratory distress syndrome

\title{
Introduction
}

All parts of the respiratory system must be considered when mechanical ventilation is initiated in patients with acute respiratory distress syndrome (ARDS). The overall mechanical characteristics are influenced by both the lung and the chest wall [1]. Increased stiffness of the chest wall that surrounds the lung requires higher pressures to ventilate the lung even when the lung itself shows normal mechanical behavior. The pressure that is required for inflation to 1 liter above resting position is defined as elastance. To assess the individual contribution of lung and chest wall to the overall respiratory system elastance, intrathoracic pressures can be obtained by esophageal manometry. The calculated transpulmonary pressures reveal lung and chest wall compliance and can then be used to individualize ventilator settings [2]. Especially in morbidly obese patients, where pleural pressures are elevated due to more weight on the thorax and abdomen, this method has been useful to guide ventilation [3]. However, high chest wall elastance due to stiffness of the thoracic cage or increased intraabdominal pressures can similarly lead to increased pleural pressures [4], without patients showing obvious clinical characteristics.

\section{Case Presentation}

A 31-year-old male patient was admitted to our hospital for coronavirus disease 2019 (COVID-19) pneumonia to receive oxygen support. After three days, he was transferred to our intensive care unit due to ARDS of increasing severity. The patient was suffering from ataxia-telangiectasia (Louis-Bar syndrome), a rare neurodegenerative, autosomal recessive disease, which, in this patient, had resulted in paresis of the torso and arms, as well as plegia of the lower extremities. He had, however, been mobile in an electric wheelchair. He received no medication prior to hospital admission and had a BMI of $20 \mathrm{~kg} / \mathrm{m}^{2}$. Louis-Bar syndrome has a poor prognosis with a median life expectancy of 19-25 years, although there are cases reaching an age of 40 years [5]. In a case series comprising critically ill patients, three of seven patients survived till intensive care unit discharge. One of seven patients had survived for three years post discharge [6]. However, this patient had exceeded the median life expectancy. Thus, a less severe disease progression was assumed. As no other negative prognostic factors were present, neither mechanical ventilation nor extracorporeal membrane oxygenation (ECMO) was contraindicated.

Non-invasive respiratory support was started for our patient with alternation between high-flow nasal cannula and non-invasive full-face mask ventilation. However, tolerance of non-invasive mask ventilation was poor and could not be improved sufficiently by the administration of sedatives. Thus, mechanical ventilation was initiated. Initial empiric positive end-expiratory pressure (PEEP) was set to $10 \mathrm{cmH}_{2} \mathrm{O}$, following the ARDS network table [7]. A driving pressure $\left(\Delta \mathrm{P}_{\mathrm{aw}}\right)$ of $25 \mathrm{cmH}_{2} \mathrm{O}$ was required to achieve sufficient ventilation, resulting in a tidal volume of $230 \mathrm{ml}(4.8 \mathrm{ml} / \mathrm{kg}$ predicted body weight (PBW)) and a plateau pressure $\left(\mathrm{P}_{\text {Plat }}\right.$ ) of $35 \mathrm{cmH}_{2} \mathrm{O}$. To maintain safer $\mathrm{P}_{\text {Plat }}$ limits, the PEEP was reduced to $7 \mathrm{cmH}_{2} \mathrm{O}$. Prone positioning was performed two hours after intubation. The patient then developed acute abdomen due 


\section{Cureus}

to acute cholecystitis. To safeguard gas exchange during surgery, veno-venous extracorporeal membrane oxygenation (ECMO) was initiated. With a blood flow of $2.5 \mathrm{l} / \mathrm{min}$ and a sweep gas flow of $3 \mathrm{l} / \mathrm{min}$, sufficient gas exchange was achieved. $\mathrm{PEEP}$ was set to $10 \mathrm{cmH}_{2} \mathrm{O}$ in an attempt to prevent de-recruitment, and $\Delta \mathrm{P}_{\text {aw }}$ was reduced to $20 \mathrm{cmH}_{2} \mathrm{O}$ to achieve a $\mathrm{P}_{\mathrm{Plat}}$ of $30 \mathrm{cmH}_{2} \mathrm{O}$. However, these settings resulted in tidal volumes $<100 \mathrm{ml}(<2.1 \mathrm{ml} / \mathrm{kg}$ PBW$)$.

Esophageal pressure $\left(\mathrm{P}_{\mathrm{es}}\right)$ monitoring was started (Table 1). End-expiratory $\mathrm{P}_{\mathrm{es}}$ was $22 \mathrm{cmH}_{2} \mathrm{O}$, and endinspiratory $\mathrm{P}_{\mathrm{es}}$ was $26 \mathrm{cmH}_{2} \mathrm{O}$. The PEEP was adjusted to $22 \mathrm{cmH}_{2} \mathrm{O}$ to achieve a transpulmonary endexpiratory pressure (PEEP minus end-expiratory $\mathrm{P}_{\mathrm{es}}$ ) of $0 \mathrm{cmH}_{2} \mathrm{O}$. In contrast, with a $\mathrm{PEEP}$ of $10 \mathrm{cmH}_{2} \mathrm{O}$, the transpulmonary end-expiratory pressure had been $-12 \mathrm{cmH}_{2} \mathrm{O}$, probably resulting in end-expiratory alveolar collapse. Inspiratory pressure was then raised to increase tidal volume to approximately $6 \mathrm{ml} / \mathrm{kg}$ PBW. A tidal volume of $300 \mathrm{ml}(6.3 \mathrm{ml} / \mathrm{kg} \mathrm{PBW})$ was accomplished with a $\mathrm{P}_{\mathrm{Plat}}$ of $41 \mathrm{cmH}_{2} \mathrm{O}$ and a resulting transpulmonary driving pressure ( $\mathrm{P}_{\mathrm{Plat}}$ minus end-inspiratory $\mathrm{P}_{\mathrm{es}}$ ) of $15 \mathrm{cmH}_{2} \mathrm{O}$.

\begin{tabular}{|c|c|c|c|c|c|}
\hline & Ventilator & Esophageal & Transpulmonary & Adjusted ventilator & Transpulmonary \\
\hline End-inspiratory pressure & 30 & 26 & 4 & 41 & 15 \\
\hline End-expiratory pressure & 10 & 22 & -12 & 22 & 0 \\
\hline Driving pressure & 20 & & 4 & 19 & 15 \\
\hline Tidal volume & $2 \mathrm{ml} / \mathrm{kg}$ PBW & & & $6 \mathrm{ml} / \mathrm{kg}$ PBW & \\
\hline
\end{tabular}

TABLE 1: First esophageal pressure measurement, calculated transpulmonary pressures, and ventilator adjustments

All pressures reported in $\mathrm{cmH}_{2} \mathrm{O} ; \mathrm{PBW}=$ predicted body weight

The measurements were repeated five hours later (Table 2). End-expiratory $\mathrm{P}_{\mathrm{es}}$ was now $19 \mathrm{cmH}_{2} \mathrm{O}$, resulting in a transpulmonary end-expiratory pressure of $3 \mathrm{cmH}_{2} \mathrm{O}$. End-inspiratory $\mathrm{P}_{\text {es }}$ was $25 \mathrm{cmH}_{2} \mathrm{O}$. The PEEP was reduced to $19 \mathrm{cmH}_{2} \mathrm{O}$ to restore a transpulmonary end-expiratory pressure of $0 \mathrm{cmH}_{2} \mathrm{O}$. To maintain an identical tidal volume, $\Delta \mathrm{P}_{\text {aw }}$ could also be reduced, resulting in a transpulmonary driving pressure of 9 $\mathrm{cmH}_{2} \mathrm{O}$.

\begin{tabular}{|c|c|c|c|c|c|}
\hline & Ventilator & Esophageal & Transpulmonary & Adjusted ventilator & Transpulmonary \\
\hline End-inspiratory pressure & 41 & 25 & 16 & 34 & 9 \\
\hline End-expiratory pressure & 22 & 19 & 3 & 19 & 0 \\
\hline Driving pressure & 19 & & 13 & 15 & 9 \\
\hline Tidal volume & 7 ml/kg PBW & & & $6 \mathrm{ml} / \mathrm{kg}$ PBW & \\
\hline
\end{tabular}

TABLE 2: Second esophageal pressure measurement (after five hours), calculated transpulmonary pressures, and ventilator adjustments

All pressures reported in $\mathrm{cmH}_{2} \mathrm{O} ; \mathrm{PBW}=$ predicted body weight

Gas exchange improved consistently over the following days. After open cholecystectomy, a complicated postoperative course developed, with acute renal failure and the need for continuous renal replacement therapy. These complications resulted in a delay in ECMO discontinuation. The ECMO was eventually discontinued after 13 days.

\section{Discussion}

The depicted case demonstrates challenges that can arise from special anatomic features in rare diseases, which can be difficult to assess at the bedside. Esophageal manometry can be used to assess chest wall 
elastance [4]. Measurements in this case clearly indicate high chest wall elastance, probably due to higher chest wall stiffness and increased intraabdominal pressure due to cholecystitis. Adjustment of respirator settings according to calculated transpulmonary pressures resulted in improved gas exchange. Our case highlights the potential of transpulmonary pressure assessment to maintain lung-protective ventilator settings during ECMO therapy. In ARDS, higher airway pressures may be required when high chest wall stiffness, obesity, or increased abdominal pressures are present [1]. When conventional airway pressure safety limits are used, initial PEEP and $\triangle \mathrm{P}_{\mathrm{aw}}$ can be inadequately low. The resulting de-recruitment poses a direct threat of further lung injury, and hypoventilation can delay the discontinuation of ECMO. Esophageal manometry and transpulmonary pressure calculations can identify optimal airway pressures and thus justify transgression of conventional limits while maintaining, or even improving, lung-protective ventilation.

\section{Conclusions}

Transpulmonary pressure calculations were useful to maintain and even improve lung-protective ventilation under ECMO therapy in this case. Not only morbidly obese patients can show severely elevated esophageal pressures. This patient with a normal BMI showed high esophageal pressure due to a severely increased chest wall elastance. Adjustment of ventilator settings to account for chest wall elastance rapidly improved gas exchange and led to the discontinuation of ECMO.

\section{Additional Information \\ Disclosures}

Human subjects: Consent was obtained or waived by all participants in this study. Conflicts of interest: In compliance with the ICMJE uniform disclosure form, all authors declare the following: Payment/services info: All authors have declared that no financial support was received from any organization for the submitted work. Financial relationships: All authors have declared that they have no financial relationships at present or within the previous three years with any organizations that might have an interest in the submitted work. Other relationships: DD is a member of SFB1425, funded by the Deutsche Forschungsgemeinschaft (DFG, German Research Foundation) - Project \#422681845.

\section{References}

1. Pelosi P, Cereda M, Foti G, Giacomini M, Pesenti A: Alterations of lung and chest wall mechanics in patients with acute lung injury: effects of positive end-expiratory pressure. Am J Respir Crit Care Med. 1995, 152:531-7. 10.1164/ajrccm.152.2.7633703

2. Talmor D, Sarge T, Malhotra A, et al.: Mechanical ventilation guided by esophageal pressure in acute lung injury. N Engl J Med. 2008, 359:2095-104. 10.1056/NEJMoa0708638

3. Eichler L, Truskowska K, Dupree A, Busch P, Goetz AE, Zöllner C: Intraoperative ventilation of morbidly obese patients guided by transpulmonary pressure. Obes Surg. 2018, 28:122-9. 10.1007/s11695-017-2794-3

4. Gattinoni L, Chiumello D, Carlesso E, Valenza F: Bench-to-bedside review: chest wall elastance in acute lung injury/acute respiratory distress syndrome patients. Crit Care. 2004, 8:350-5. 10.1186/cc2854

5. Crawford TO, Skolasky RL, Fernandez R, Rosquist KJ, Lederman HM: Survival probability in ataxia telangiectasia. Arch Dis Child. 2006, 91:610-11. 10.1136/adc.2006.094268

6. Lockman JL, Iskander AJ, Bembea M, Crawford TO, Lederman HM, McGrath-Morrow S, Easley RB: The critically ill patient with ataxia-telangiectasia: a case series. Pediatr Crit Care Med. 2012, 13:e84-90. 10.1097/PCC.0b013e318219281c

7. Brower RG, Matthay MA, Morris A, Schoenfeld D, Thompson BT, Wheeler A: Ventilation with lower tidal volumes as compared with traditional tidal volumes for acute lung injury and the acute respiratory distress syndrome. N Engl J Med. 2000, 342:1301-8. 10.1056/NEJM200005043421801 